\title{
Fenologia e visitantes florais de Erythrina crista-galli L. (Leguminosae: Faboideae) em Santa Maria, Rio Grande do Sul, Brasil
}

\author{
Raimunda Alice Coimbra Vieira Costa ${ }^{1 *}$ \\ Ana Beatriz Barros de Morais $^{2}$ \\ 'Programa de Pós-Graduação em Biodiversidade Animal \\ Centro de Ciências Naturais e Exatas, Universidade Federal de Santa Maria - UFSM \\ ${ }^{2}$ Departamento de Biologia, Centro de Ciências Naturais e Exatas - UFSM \\ Faixa de Camobi, km 09, CEP 97105-900, Santa Maria - RS, Brasil \\ *Autora para correspondência \\ alice_coimbra28@yahoo.com.br
}

Submetido em 10/09/2007

Aceito para publicação em 11/04/2008

\section{Resumo}

Erythrina crista-galli é uma espécie característica do bioma Pampa, também usada com fins ornamentais em arborização urbana. E. crista-galli floresce mais intensamente de novembro a dezembro. A antese inicia entre $7 \mathrm{~h}-11 \mathrm{~h}$, e as flores têm duração de cinco dias. Um total de 1.275 visitas florais foi registrado em $57 \mathrm{~h}$ de observações. Abelhas da família Apidae (Trigona spinipes e Apis mellifera) foram os visitantes florais mais freqüentes $(88,23 \%$ ), seguidos de moscas (Muscidae - 5,50\%), formigas (Formicidae - 2,35\%), vespas (Vespidae $-1,56 \%$ ) e besouros (Chrysomelidae - 1,56\%). As flores também foram visitadas por beija-flores da família Trochilidae (Chlorostilbon aureoventris) (0,79\%). A abelha T. spinipes foi observada em todos os horários e apresentou comportamento de possível polinizadora, juntamente com A. mellifera e o beija-flor C. aureoventris. E. crista-galli é autocompatível, apresentando produção de frutos e sementes após a polinização manual e sob condições naturais.

Unitermos: Chlorostilbon aureoventris, Erythrina crista-galli, fenologia, Trigona spinipes

\section{Abstract}

Phenology and floral visitors of Erythrina crista-galli L. (Leguminosae: Faboideae) in Santa Maria, Rio Grande do Sul, Brazil. Erythrina crista-galli is a characteristic species of the Pampa biome also used as an ornament in urban arborization. Erythrina crista-galli flourishes more intensively from November to December. Anthesis starts around 7:00 am to 11:00 am, and flowers last five days. A total of 1,275 floral visits were registered over $57 \mathrm{~h}$ of observations. Apidae bees (Trigona spinipes and Apis mellifera) were the most frequent visitors $(88.23 \%$ ), followed by Muscidae flies (5.50\%), Formicidae ants (2.35\%), Vespidae wasps (1.56\%), and Chrysomelidae beetles (1.56\%). Trochilidae hummingbirds (Chlorostilbon aureoventris) $(0.79 \%)$ also visited the flowers. Trigona spinipes was observed at throughout the daytime and behaved as a probable pollinator, along with $A$. mellifera and $C$. aureoventris. E. crista-galli is autocompatible, producing fruits and seeds after manual pollination and under natural conditions.

Key words: Chlorostilbon aureoventris, Erythrina crista-galli, phenology, Trigona spinipes 


\section{Introdução}

A família Leguminosae possui cerca de 630 gêneros e 18.000 espécies (Judd et al., 1999), e é particularmente abundante em países tropicais, como o Brasil, onde se destaca na composição das matas nativas (Marchiori, 1997). A região sul é muito rica em espécies, presentes nos mais diferentes tipos de vegetação e hábitats (Miotto, 1993).

O gênero Erythrina (Leguminosae: Faboideae) reúne 108 espécies de árvores ornamentais e arbustos, dispersas pelas regiões tropicais e subtropicais do mundo. A flora sul-rio-grandense conta com duas espécies nativas: a corticeira-do-banhado (Erythrina crista-galli L.) e a corticeira-do-mato (Erythrina falcata Benth.) (Marchiori, 1997).

Os grupos animais mais importantes para a polinização cruzada das plantas são insetos, aves e morcegos (Pellmyr, 2004). Embora as Leguminosae sejam polinizadas principalmente por abelhas (Arroyo, 1981), o gênero Erythrina foge a esse padrão, sendo polinizado por beija-flores (Toledo, 1974; Faegri e Van der Pijl, 1980; Arroyo, 1981; Endress, 1996). De acordo com Faegri e Van der Pijl (1980), suas flores possuem características morfo-fisiológicas relacionadas com a síndrome de ornitofilia: néctar abundante e pouco viscoso, ausência de odores, antese diurna e corola tubulosa geralmente laranja ou vermelha.

No Brasil, as flores de Erythrina são visitadas por insetos (principalmente abelhas) e aves (beija-flores e Passeriformes), ambos os grupos animais apresentando comportamento de possíveis polinizadores (Vitali-Veiga e Machado, 2000; Ragusa-Neto, 2002; Almeida e Alves, 2003; Mendonça e Anjos, 2006).

Erythrina crista-galli é uma espécie encontrada no bioma Pampa e característica dessa paisagem sulriograndense bastante ameaçada em sua conservação; além disso, também é usada com fins ornamentais em arborização urbana. Em estudo realizado em florestas cultivadas e naturais da Argentina e Uruguai, em latitudes próximas ao Rio Grande do Sul, Galetto et al. (2000) registraram as abelhas Apis mellifera e Xylocopa sp. como os principais polinizadores de E. cristagalli, além de quatro espécies de beija-flores. No Rio
Grande do Sul, até o momento, não existe nenhum estudo publicado sobre a biologia reprodutiva e os visitantes florais dessa espécie. Assim, o presente trabalho teve como objetivos caracterizar a fenologia, incluindo aspectos do sistema reprodutivo, e registrar os visitantes florais e, dentre eles, os possíveis polinizadores de E. crista-galli, em região urbana da cidade de Santa Maria, RS.

\section{Material e Métodos}

A cidade de Santa Maria está localizada no centro geográfico do Estado do Rio Grande do Sul (2942’S e $\left.53^{\circ} 42^{\prime} \mathrm{W}\right)$. O clima é do tipo temperado, mesotérmico brando, de acordo com a classificação de Köppen, com precipitação média anual de $1.732 \mathrm{~mm}$ e temperatura média anual oscilando entre $18^{\circ} \mathrm{C}$ e $20^{\circ} \mathrm{C}$ (Nimer, 1990). A vegetação pertence ao domínio da Floresta Estacional Decidual da Fralda da Serra Geral (Pereira et al., 1989). As árvores estudadas localizam-se no Campus Camobi da Universidade Federal de Santa Maria (UFSM) $(n=4)$ e num terreno baldio $(n=2)$ do Bairro Parque Pinheiro Machado.

A fenologia das plantas foi determinada quinzenalmente, no período de março de 2002 a fevereiro de 2003, através das seguintes fenofases: queda foliar, brotação, floração e frutificação. Considerou-se queda de folhas quando elas: 1) perdiam a cor adquirindo um tom alaranjado; 2) caíam com facilidade ao ventar; 3) estavam em grande quantidade debaixo das plantas; 4) deixavam espaços vazios nos galhos e na copa das árvores. Considerou-se o estágio de brotação a partir do aparecimento de pequenas folhas brilhantes, de cor verde clara. O estágio de floração foi caracterizado pela ocorrência de botões e antese. O estágio de frutificação foi considerado aquele em que se observou a ocorrência de frutos jovens e frutos maduros. A antese foi observada em 20 botões marcados individualmente.

Durante os meses de floração, os visitantes florais foram observados em horários alternados, entre os períodos da manhã ( $7 \mathrm{~h}$ às $12 \mathrm{~h}$ ) e tarde (13h às $18 \mathrm{~h}$ ), diretamente nas flores, a olho nu, ou com auxílio de binóculo, nas seis árvores estudadas. Procurou-se fazer observações diárias, com uma hora de duração por 
planta, no máximo em três árvores por dia. Todos os visitantes que pousavam nas flores foram identificados e seu comportamento foi registrado em relação a número de visitas, atividade e tempo de permanência nas flores e contato com os órgãos reprodutivos. A identificação taxonômica foi feita com uso de bibliografia especializada para insetos (Borror e De Long, 1988) e aves (Narosky e Yzurieta, 2003) e consulta a especialistas dos dois grupos. Os visitantes considerados possíveis polinizadores foram identificados até o nível de espécie enquanto os outros até família apenas. Os insetos foram coletados com auxílio de rede entomológica ou potes de coleta, sacrificados, e posteriormente alfinetados, fixados a seco, e etiquetados (Borror e De Long, 1988). Esse material testemunho encontra-se depositado na Coleção de Referência do Laboratório de Interações Inseto Planta, Departamento de Biologia, CCNE/UFSM.

Devido à impossibilidade de isolar botões individuais para se fazer os testes de polinização, inflorescências ainda em botão foram isoladas como um todo e envolvidas completamente com tecido fino. Os testes foram feitos em três árvores ( $\mathrm{n}=7$ inflorescências em cada uma) e seguiram metodologia proposta por Dafni (1992). Durante a pré-antese, algumas flores foram emasculadas para se testar a apomixia. Outras foram polinizadas manualmente com pólen da mesma flor (autogamia); e outras com pólen proveniente de flores diferentes da mesma planta (geitonogamia). Através da transferência manual de pólen de flores de plantas diferentes foi testada a polinização cruzada (xenogamia). Para verificação da existência ou não de autopolinização espontânea, outras flores ensacadas permaneceram intactas. Finalmente, algumas flores foram marcadas para se verificar a formação de frutos e sementes em condições naturais.

\section{Resultados e Discussão}

A antese floral de E. crista-galli é diurna e o início da abertura foi entre 7 e 11h. As flores têm duração de cinco dias e o pólen permanece disponível no primeiro dia de antese.

Depois de um pequeno episódio em março de 2002, a floração de E. crista-galli voltou a ocorrer a partir de final de outubro, atingindo sua intensidade máxima em novembro, com término em dezembro (Tabela 1). Esse período de menor intensidade de floração também foi constatado por Galetto et al. (2000) no Uruguai e Argentina, porém Marchiori (1997) e Backes e Irgang (2002) descrevem apenas um período, aquele correspondente à época de maior intensidade (outubro a dezembro), para essa espécie no Rio Grande do Sul. Cada inflorescência produziu em média $65,4 \pm 5,52$ flores $(n=10)$.

TABELA 1: Fenologia de Erythrina crista-galli em Santa Maria, RS, no período de março de 2002 a fevereiro de 2003.

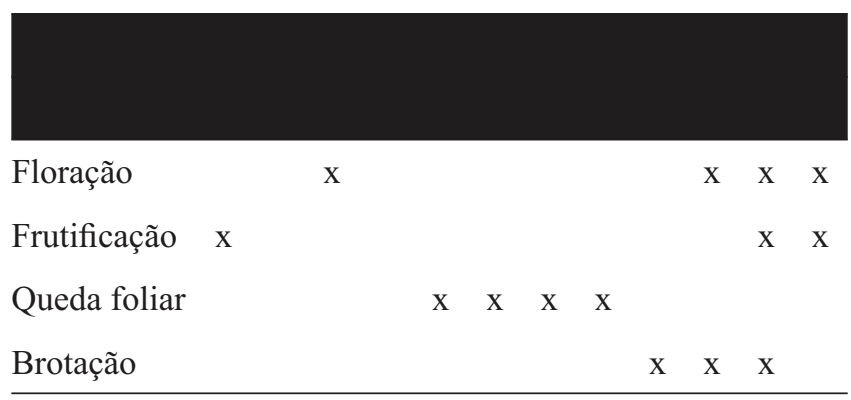

A frutificação ocorreu nos meses de novembro e dezembro (Tabela 1). A maturação das vagens ocorreu no mês de janeiro de 2003 (Tabela 1).

No total de $57 \mathrm{~h}$ de observação, 1.275 visitas florais foram registradas (Tabela 2). As abelhas foram os visitantes florais mais freqüentes $(88,23 \%)$. Também foram observados moscas, formigas, vespas, besouros e beija-flores, em proporções variadas (Tabela 2). A maior atividade dos visitantes florais ocorreu nas horas mais quentes dos dias ensolarados e com pouco vento, e a menor em dias nublados e chuvosos.

O único inseto presente durante todos os horários e dias de observação foi Trigona spinipes (Fabricius, 1793). Essa abelha aparecia em todos os horários de observações, solitária ou em grupos de cinco a seis indivíduos, sendo mais freqüente nos períodos entre as 9 e $12 \mathrm{~h}$ da manhã e 13 e $16 \mathrm{~h}$ da tarde. Trigona spinipes dirigia-se diretamente para a flor, pousando nas anteras com a parte ventral do corpo, e iniciava a retirada do pólen com auxílio das peças bucais e dos primeiros pares de pernas. Ao manipular o pólen, o estigma também era tocado. Após explorar todas as anteras e deixá-las 
totalmente sem pólen, fazia orifícios na base da flor para alcançar e extrair o néctar, permanecendo em seu interior por cerca de 5 a $10 \mathrm{~min}$. O comportamento de procura de pólen também foi observado durante a préantese em E. crista-galli, através de orifícios feitos no ápice do botão.

TABELA 2: Visitantes florais de Erythrina crista-galli, em Santa Maria, Rio Grande do Sul, 20022003.

\begin{tabular}{l|l|l|c|c}
\hline \multicolumn{5}{|l}{} \\
\hline \multirow{4}{*}{ Insetos } & Coleoptera & Chrysomelidae & 20 & 1,56 \\
\cline { 3 - 5 } & Diptera & Muscidae & 70 & 5,50 \\
\cline { 3 - 5 } & Hymenoptera & $\begin{array}{l}\text { Formicidae } \\
\text { Apidae: }\end{array}$ & 30 & 2,35 \\
\cline { 3 - 5 } & $\begin{array}{l}\text { Apis mellifera } \\
\text { Avesidae }\end{array}$ & 54 & 4,23 \\
\hline & $\begin{array}{l}\text { Apidae: } \\
\text { Trigona spinipes }\end{array}$ & 1.071 & 84,00 \\
\hline Total & Trochilidae & $\begin{array}{l}\text { Chlorostilbon } \\
\text { aureoventris }\end{array}$ & 10 & 0,79 \\
\hline
\end{tabular}

Apis mellifera apresentou um comportamento semelhante a $T$. spinipes, em relação aos horários de visitação, à coleta de pólen e ao contato com o estigma na flor de E. crista-galli. Essa abelha aproveitou os orifícios na base da flor, já feitos por $T$. spinipes para sorver o néctar, realizando o assim chamado roubo secundário, comportamento prejudicial para a polinização, pois o inseto não entra em contato com os órgãos reprodutivos da flor.

De modo geral, $T$. spinipes e A. mellifera possuem hábitos generalistas e oportunistas e exploram intensivamente os recursos mais abundantes, sendo consideradas pilhadoras em algumas espécies vegetais ou polinizadoras em outras (Pirani e Cortopassi-Laurino, 1993; Balestieri e Machado, 1998) inclusive polinizando espécies de Erythrina (Galetto et al., 2000; VitaliVeiga e Machado, 2000). No presente estudo, devido ao seu comportamento de forrageio nas flores e contato com o estigma, elas foram consideradas possíveis polinizadoras de E. crista-galli.

A maioria dos outros grupos de insetos visitantes, com exceção de Muscidae (Tabela 2), teve freqüência baixa de visitas nas flores de E. crista-galli. As moscas utilizavam as flores como locais para acasalamento, mas não tocavam os órgãos reprodutivos, permaneciam no máximo por um minuto, e depois voavam ao seu redor para pousar nos galhos. As formigas caminhavam nos galhos e flores e raramente entravam no interior das flores, e, ao fazê-lo, não tocavam seus órgãos reprodutivos. As vespas permaneciam por cerca de cinco minutos e também não tocavam os órgãos reprodutivos, nas poucas vezes em que foram observadas. Finalmente, os besouros visitavam as flores de E. crista-galli, mas saíam em seguida, permanecendo nos galhos ou raspando as folhas ou ainda utilizando as flores também como locais para acasalamento.

Esses grupos de insetos visitantes foram considerados possíveis polinizadores ou pilhadores, devido ao seu comportamento de forrageio por néctar e/ou pólen em outros estudos (Vitali-Veiga et al., 1999; Galetto et al., 2000; Vitali-Veiga e Machado, 2001; Nogueira e Arruda, 2006). No presente trabalho, no entanto, não foram considerados prováveis polinizadores de E. crista-galli, devido ao seu comportamento observado.

No presente estudo, além dos insetos, também foram observados beija-flores Chlorostilbon aureoventris (d' Orbigny and Lafresnaye, 1838) visitando as flores de duas árvores de E. crista-galli (Tabela 2), principalmente no período entre as 9 e $10 \mathrm{~h}$ da manhã. Eles inseriam o bico na flor (ou num orifício já feito por $T$. spinipes), sorviam o néctar ali existente, e podiam ou não tocar os órgãos reprodutivos, num período de dois a cinco segundos. Visitavam várias inflorescências na mesma árvore em pouco tempo, saindo, e retornando cerca de 20 a 30min depois. Essa mesma espécie de beija-flor foi registrada polinizando E. speciosa em ambiente urbano em São Paulo (Vitali-Veiga e Machado, 2000) e Paraná (Mendonça e Anjos, 2006). Galetto et al. (2000) também consideraram-no polinizador efetivo, juntamente com abelhas e outras três espécies de beija-flores, na Argentina e Uruguai.

Assim, C. aureoventris pode também ser considerado possível polinizador de E. crista-galli em ambiente urbano em Santa Maria, apesar de não ter sido observado em todas as árvores. A presença de um ninho da abelha T. spinipes, nas proximidades de algumas árvores estudadas no Campus UFSM, pode ter impedido 
o beija-flor de visitá-las pois o comportamento agressivo dessa espécie de abelha já foi observado em relação a beija-flores e outras espécies de abelhas (Sick, 1997; Balestieri e Machado, 1998).

Erythrina crista-galli mostrou-se autocompatível em Santa Maria. A maior produção de frutos ocorreu em condições naturais (44), seguida por xenogamia (17) e geitonogamia (7) (Tabela 3). Não ocorreu formação de frutos no teste de apomixia (Tabela 3). No entanto, esses resultados só podem ser comparados proporcionalmente em relação ao sucesso (Tabela 3), cujo maior valor foi obtido em condições naturais (5,9\%), seguido por geitonogamia, xenogamia e autopolinização espontânea, que tiveram valores iguais $(1,53 \%)$.

TABELA 3: Resultados dos testes de polinização em Erythrina crista-galli, Santa Maria, RS, 2002-2003.

\begin{tabular}{lcccc} 
& & & & \\
Apomixia & 67 & 0 & 0 & 0 \\
Autogamia & 60 & 1 & 0 & 0 \\
Geitonogamia & 65 & 7 & 1 & 1,53 \\
Xenogamia & 65 & 17 & 1 & 1,53 \\
Autopolinização & 65 & 4 & 1 & 1,53 \\
espontânea & & & 20 & 5,9 \\
Condições naturais & 335 & 44 & 20 \\
\hline
\end{tabular}

$\mathrm{Fl}=$ número de flores; $\operatorname{Fr}(\mathrm{N})=$ número de frutos produzidos; $\operatorname{Fr}\left(\mathrm{N}^{*}\right)$ = número de frutos que completaram o desenvolvimento; Sucesso = percentagem de frutos que completaram o desenvolvimento.

Galetto et al. (2000) encontraram resultados semelhantes na formação de frutos de E. crista-galli em condições naturais $(5,4 \%)$, e valores maiores em quase todos os outros testes, sendo que autogamia foi o sistema predominante de reprodução (13,9\%). Em florestas naturais e cultivadas no Uruguai e Argentina, essa espécie foi considerada autocompatível, apresentando baixa fecundidade e altas taxas de aborto de flores e frutos (Galetto et al. 2000).

No presente trabalho, o baixo número de frutos que completou o desenvolvimento pode ter sido conseqüência do excesso de chuva e vento, que causaram queda de muitas flores e botões. Pode ter contribuído para isso o fato de muitas das árvores estudadas encontrarem-se isoladas, em meio à vegetação herbácea e, conseqüentemente mais exposta às intempéries. No pe- ríodo mais intenso de floração, em novembro de 2002, a precipitação foi de $243,4 \mathrm{~mm}$, enquanto que o valor da normal climatológica (1961-1990) para o mês de novembro é de apenas 132,2mm (Fonte: Estação Climatológica Principal de Santa Maria). Fatores antrópicos também ocorreram, na forma de danos mecânicos aos galhos com inflorescências no Campus UFSM, incluindo algumas marcadas, cujos resultados tiveram que ser excluídos das análises finais.

Uma outra explicação para baixa produção de frutos em condições naturais seria a falta de recursos disponíveis na planta ou a grande presença de polinizadores ocasionais (pilhadores de néctar ou pólen), conforme observado por Vitali-Veiga e Machado (2001), em G. triacanthos. No caso de E. crista-galli, esse parece ser o padrão, pois, além dos resultados acima mencionados no Uruguai e Argentina, a repetição dos testes de polinização em Santa Maria nos anos de 2005 e 2006 (Costa, 2006) também resultou em valores baixos de produção de frutos. Além disso, estudos feitos recentemente com E. falcata, na Argentina, também registraram baixa produção de frutos e sementes (Etcheverry e Alemán, 2005).

Os frutos obtidos nos experimentos de polinização manual e em condições naturais levaram cerca de 60 dias para completar seu desenvolvimento. O número de sementes produzidas por fruto de E. crista-galli variou entre um e três, nos 23 frutos que completaram seu desenvolvimento, dentro do intervalo registrado por Backes e Irgang (2002), que foi de um a seis.

Em ambiente urbano de Santa Maria, E. cristagalli atrai visitantes florais de grupos animais variados, principalmente insetos, e dentre eles, as abelhas $T$. spinipes e A. mellifera, consideradas possíveis polinizadoras, juntamente com o beija-flor $C$. aureoventris. Trigona spinipes e C. aureoventris são espécies nativas e assim, recomenda-se a continuação e a ampliação desses estudos em ambiente natural, para comparação com os resultados aqui obtidos. Assim, seria possível traçar um diagnóstico mais preciso para garantir o manejo, viabilidade e manutenção das populações de E. crista-galli e em ambiente urbano, onde se constituem fonte de recursos alimentares para espécies da fauna nativa. 


\section{Agradecimentos}

Aos Dr. Birgit Harter-Marques, UNESC, e Dinísio Link, UFSM, pela identificação das abelhas e insetos, respectivamente; a Vagner Luis Camilotti, pela confirmação na identificação do beija-flor; e à $\mathrm{Dr}^{\mathrm{a}}$ Sônia Maria Eisinger, UFSM, pelo auxílio com os dados fenológicos. Aos consultores pelos valiosos comentários ao artigo.

\section{Referências}

Almeida, E. M.; Alves, M. A. 2003. Comportamento de aves nectarívoras em Erythrina speciosa Andrews. (Leguminosae-Papilionoideae) em uma área de floresta atlântica, Ilha Grande, Rio de Janeiro. Revista de Etologia, 5: 15-21.

Arroyo, K. M. T. 1981. Breeding systems and pollination biology in Leguminosae. In: Polhil, R. M. \& Raven, P. H. (eds). Advances in legumes systematics. Royal Botanic Gardens, Kew, UK, p.723769.

Backes, P.; Irgang, B. 2002. Árvores do Sul - guia de identificação \& interesse ecológico. Instituto Souza Cruz, Santa Cruz do Sul, Brasil, 326 pp.

Balestieri, F. C. L. M.; Machado, V. L. L. 1998. Entomofauna visitante de sibipiruna (Caesalpinia peltophoroides Benth) (Leguminosae) durante o seu período de floração. Revista Brasileira de Entomologia, 41: 2-4.

Borror D. J.; De Long, D. M. 1988. Introdução ao estudo dos insetos. Edgard Blucher, São Paulo, Brasil, 653 pp.

Costa, R. A. C. V. 2006. Visitantes florais de Erythrina crista-galli L. e $E$. falcata Benth (Leguminosae: Faboideae) na região urbana de Santa Maria, Rio Grande do Sul, Brasil. Dissertação de Mestrado, Universidade Federal de Santa Maria, Brasil, 76 pp.

Dafni, A. 1992. Pollination ecology: a practical aproach. Oxford University, Oxford, UK, 250 pp.

Endress, P. J. 1996. Diversity and evolutionary biology of tropical flowers. Cambridge University Press, New York, USA, 551 pp.

Etcheverry, A. V.; Alemán, C. E. T. 2005. Reproductive biology of Erythrina falcata (Fabaceae: Papilionoideae). Biotropica, 37 (1): 54-63.

Faegri, K.; Van Der Pijl, L. 1980. The principles of pollination ecology. $3^{\text {rd }}$ ed. Pergamon, Londres, UK, 244 pp.

Galetto, L.; Bernadello, I. C.; Isele, J.; Vesprini, G.; Speroni, G.; Berduc, A. 2000. Reproductive biology of Erythrina crista-galli (Fabaceae). Annals of the Missouri Botanical Garden, 87: 127145 .
Judd, W. S.; Campbell, C. S.; Kellogg, E. A.; Stevens, P. F. 1999. Plants systematic: a phylogenetic approach. Sinauer Associates, Sunderland, USA, 464 pp.

Marchiori, J. N. C. 1997. Dendrologia das Angiospermas: Leguminosas. Ed. UFSM, Santa Maria, Brasil, 200 pp.

Mendonça e Anjos 2006. Feeding behavior of hummingbirds and percing birds on Erytrina speciosa Andrews ( Fabaceae) flowers in an urban area, Londrina, Paraná, Brazil. Revista Brasileira de Zoologia 23(1): $42-49$

Miotto, S. T. 1993. Situação dos estudos taxonômicos da família Leguminosae na região sul do Brasil. Napea, 9: 5-11.

Narosky,T \& Izurieta, D. 2003. Aves de Argentina Y Uruguai: guia para la identificación: edición de oro. $15^{\mathrm{a}}$ ed. Buenos Aires, $348 \mathrm{pp}$.

Nimer, E. 1990. Clima. In: Fundação Instituto Brasileiro de Geografia e Estatística (eds.). Geografia do Brasil: Região Sul, v. 2. SERGRAF/ IBGE, Rio de Janeiro, Brasil, p.151-187.

Nogueira, E. M. L.; Arruda, V. L. V. 2006. Fenologia reprodutiva, polinização e sistema reprodutivo de Sophora tomentosa L. (Leguminosae - Papilionoideae) em restinga da praia da Joaquina, Florianópolis, sul do Brasil. Biotemas, 19 (2): 29-36.

Pellmyr, O. 2004. Pollination by animals. In: Herrera, C. M. \& Pellmyr, O. (eds). Plant-animal interactions: an evolutionary approach. Blackwell, Malden, USA, p.157-184.

Pereira, P. R. B.; Garcia Netto, L. R.; Borin, C. J. A.; Sartori, M. G. B. 1989. Contribuição à geografia física do município de Santa Maria: unidades de paisagem. Geografia - Ensino \& Pesquisa, 3: 37-68.

Pirani, J. R.; Cortopassi-Laurino, M. 1993. Flores e abelhas em São Paulo. EDUSP, São Paulo, Brasil, 192 pp.

Ragusa-Neto, J. 2002. Explotation of Erythrina dominguezii Hassl. (Fabaceae) nectar by perching birds in a dry forest in western Brazil. Brazilian Journal of Biology, 62 (4b): 877-883.

Sick, H. 1997. Ornitologia brasileira. Nova Fronteira, Rio de Janeiro, $867 \mathrm{pp}$.

Toledo, V. M. 1974. Observation on the relationship between hummingbirds and Erythrina species. Lloydia, 37: 482-487.

Vitali-Veiga, M. J.; Dutra, J. C. S.; Machado, V. L. L. 1999. Visitantes florais de Lagerstroemia speciosa Pers. (Lythraceae). Revista Brasileira de Zoologia, 16: 397-407.

Vitali-Veiga, M. J.; Machado, V. L. L. 2000. Visitantes florais de Erythrina speciosa Andr. (Leguminosae). Revista Brasileira de Zoologia, 17: 369-383.

Vitali-Veiga, M. J.; Machado, V. L. L. 2001. Entomofauna visitante de Gleditsia triacanthos L. - Leguminosae durante o seu período de floração. Bioikos, 15: 29-38. 